\title{
ANÁLISE GRÁFICA PARA REFLEXÕES DE GÊNERO: O CASO DOS ALMANACHS DE PELOTAS (1913-1935)
}

Paula Garcia Lima

Universidade Federal de Pelotas

paulaglima@gmail.com

Francisca Ferreira Michelon

Universidade Federal de Pelotas

fmichelon.ufpel@gmail.com

Caroline Farias Ferreira

Universidade Federal de Pelotas

carolinefariasferreira@gmail.com

Resumo: O texto busca pensar as construções de gênero, alinhadas a análises gráficas. Para tal, tomaram-se como objetos de estudo os Almanachs de Pelotas. Este periódico circulou na cidade de Pelotas-RS, no período entre 1913 e 1935, tendo como temas assuntos de utilidades diversas, de entretenimento e, principalmente, de propaganda da modernização da cidade e das grandes ações de seus conterrâneos. Entremeado a esses assuntos, observou-se um grande número de discursos de gênero com teor conservador, inerente ao ambiente da cidade. Uma breve introdução sobre a publicação e apreciações gráficas em itens como capas, ilustrações e fotografias é o que se apresenta, de forma a verificar, por meio desses, possíveis atribuições de gênero, principalmente no que tange às mulheres. Pela data de circulação do periódico, trata-se de um estudo que se debruça sobre o passado, no entanto, funda-se na compreensão de gênero como uma construção cultural (na qual se inserem os produtos midiáticos) cujos discursos, continuamente repetidos, ecoam através dos tempos.

Palavras-chave: Almanachs de Pelotas, análise gráfica, gênero.

Abstract: This text aims thinking gender constructions, aligned with graphical analysis. For this goal, those were taken as objects of study the "Almanachs de Pelotas". This newspaper circulated in the city of Pelotas-RS, in the period between 1913 and 1935, with matters of various utilities, of entertainment and mainly of city, modernization, advertisement and great deeds of its countrymen as subject. Interspersed with these issues, there was a large number of gender discourse with conservative content inherent in the city environment. A brief introduction about the publication and graphic assessments on items such as covers, illustrations and photographs is what is presented in order to verify, through these, possible assignments 
of gender, especially with regard to women. By the date of periodic circulation, it is a study that focuses on the past. However, it is based on the understanding of gender as a cultural construction (in which the media products are inserted), whose discourses, continuously repeated, echo over time.

Keywords: Almanachs de Pelotas, graphical analysis, gender.

\section{INTRODUÇÃO}

Aspectos relativos às definições de gênero permanecem sendo tema de interesse para muitas áreas do conhecimento, dado o fato de que as lentas mudanças culturais podem ser descontínuas e em diferentes níveis, conforme o aspecto ou local que se tenha como referência para a observação. É possível que em determinado contexto, conflitos de gênero possam ser considerados superados, pode ser que se entendam inúmeras as conquistas obtidas, principalmente no tangente às mulheres. Por outro lado, basta mudar o recorte temporal e as diferenças de tratamento para com as mulheres tomam uma desproporção tão grande que se elucida ocorrências ainda verificáveis nos dias atuais, como se fosse possível flexionar o tempo e os fatos passados ainda se mantivessem no presente.

Embora o parágrafo acima observe aspectos avaliados no contexto presente e com interesses e preocupações que emergem neste mesmo tempo, o texto que aqui se apresenta, para a reflexão proposta, debruça-se em artefatos pretéritos: os Almanachs de Pelotas, editados no município gaúcho que nomeia o periódico, no período de 1913 a 1935. O enfoque em objetos do passado parte da compreensão de que a construção de gênero é um processo cultural, histórico e relacional, entendimento que tem em Scott (1995, p.74) - importante teórica de gênero justificativa nesse sentido. A autora diz que para que se compreenda que as mulheres tiveram história, e que esta história não foi uma história isolada, é necessário que se faça uma análise que correlacione experiências femininas com as masculinas no passado e ainda de forma conectada com as práticas históricas presentes.

Entende-se que objetos da mídia, como esses impressos do início do século XX, são elementos que possuem uma influência significativa na definição de comportamentos e de papéis, continuamente produzindo e/ou continuamente lembrando as visões de mundo a serem trilhadas. No presente caso, observou-se uma publicação que, possivelmente, influiu ou refletiu o contexto no qual circulou. Esses objetos, por um lado, são tomados como exemplares representativos do papel da mídia em tais construções, cujas ponderações desencadeadas poderiam ser aplicadas para uma mídia atual; e, por outro, como elementos que permitem pensar nas atribuições de gênero que, mesmo através das décadas, permanecem reverberando.

O Almanach de Pelotas, fundado por Dr. Antonio Gomes da Silva, Ignácio Alves Ferreira e Capitão Florentino Paradeda, assim como os demais títulos desta tipologia de publicação, foram editados anualmente, totalizando 23 edições. Versavam sobre uma grande variedade de temas, desde aqueles de utilidade pública até aqueles cujo objetivo era entreter e divertir o leitor. No entanto, os assuntos que apareciam com veemente frequência eram as expressões de modernidade da cidade e as grandes ações de seus conterrâneos. 
Contudo, sob o seu discurso moderno, percebeu-se um viés conservador e uma série de discursos de gênero, principalmente acerca das "desejáveis" atribuições femininas. Percebeu-se como era uma publicação marcadamente voltada ao público masculino já na leitura do prefácio de sua primeira edição, que apresenta o periódico para os seus leitores dizendo que "é elle ainda quem te lembra o cumprimento dos teus deveres de cidadão e dos teus encargos de contribuinte, e, para amenisar-te os ócios de chefe de família e de homem de trabalho (...)" (Prefácio Almanach de Pelotas, 1913, p. 3, grifo nosso). O trecho que indica as estipulações de gênero, indica a quem se direcionava. Além disso, na pesquisa realizada observou-se que as aparições femininas em ilustrações e fotografias é bastante reduzida se comparada à presença masculina, além de ser muito menor, também, o número de colaborações de mulheres assinando textos.

A seguir, então, discute-se acerca destas inquietações colocadas, tendo como foco, uma análise gráfica dos Almanachs de Pelotas. Alinha-se, desta forma, design e construção de gênero.

\section{ANÁLISE GRÁFICA PARA REFLEXÕES DE GÊNERO}

Os Almanachs foram confeccionados a partir da técnica tipográfica com a presença de clichês fotográficos e, ainda, de ilustrações. Nas publicações de 1913 a 1920 as impressões foram realizadas pelas Officinas Typográficas do Diário Popular; de 1921 a 1928 as edições foram impressas na Tipografia A Guarany; e de 1929 a 1935 as impressões se deram nas Oficinas tipográficas da Livraria do Globo (GASTAUD e SILVA, 2010, p. 12) (LESCHKO, 2011, p.53). Seu miolo era impresso em papel jornal (de baixa gramatura e poroso) e, suas capas, em papel mais espesso e, em alguns casos, fazendo uso de outras técnicas de impressão. Suas dimensões ficavam entre $13 \times 19 \mathrm{~cm}$ e 13×21 $\mathrm{cm}$, no formato fechado, dependendo da edição. No formato aberto há maiores variações devido às diferenças no número de páginas em cada ano, interferindo na altura da lombada e, consequentemente, na largura no formato aberto.

Em termos gerais, os estilos orientadores da composição gráfica dos Almanachs de Pelotas mesclaram influências do Art Nouveau e do Art Déco, embora o primeiro tenha em suas aparições maior frequência e constância ao longo dos anos e das edições. O Art Nouveau foi um estilo decorativo internacional inspirado na organicidade vegetal e nas formas femininas, compondo-se de linhas fluidas e curvas assimétricas, as quais se somavam a aplicação de cores vivas (DENIS, 2000, p. 87-88) (MEGGS, 2009, p. 248).

O Art Nouveau, embora muitas vezes associado a um estilo meramente decorativo, segundo Meggs (2009, p. 249) e Barros et al. (1999, p. 245-246), ele teve importância fundamental no desenvolvimento do design. Considerado uma evolução do historicismo que predominou no século XIX, estabelecendo uma fase inicial do movimento moderno, ele rompeu com moldes gráficos rígidos e o caráter servil das formas dos estilos anteriores. Por terem sido os primeiros passos do referido movimento, o Art Nouveau exaltava o novo e o atual e, por ter sido um estilo criado tanto por pintores quanto por arquitetos e designers, de diferentes pontos geográficos, teve como resultado obras também diversas em suas características, refletindo as contradições da era moderna. Dentro desta diversidade encontram-se, em alguns exemplos, formas mais duras, angulares e geometrizadas (DENIS, 2000, p. 87-88). 
As características acima, contudo, são mais exemplares e evidentes do Art Déco, estilo imediatamente sucessório. Comparado às manifestações do Art Nouveau, é identificado como sendo mais mecânico, mais construtivo e mais geométrico e, logo, renegando as formas florais, orgânicas e os excessos ornamentais (Idem, p. 92-93).

Tais estilos, no Brasil, além de afastados geograficamente do seu contexto de origem, foram tardios, separando-se, assim, dos significados culturais que os geraram. Por aqui, a aplicação do Art Nouveau e do Art Déco serviu como expressão do novo e da busca pela tão desejada modernidade (Idem, p. 92-93). A instauração tardia e quase concomitante dos estilos no país fez com que os mesmos se tornassem o prolongamento um do outro, de forma que as suas distintas características acabassem sendo aplicadas conjuntamente em uma mesma composição, em um processo de intercâmbio que não deixou clara a ruptura entre ambos (Idem, p. 88-94).

Nos Almanachs de Pelotas, o emprego dos referidos estilos bem como de concomitância de seu uso, encontram-se em muitos exemplares, como nos casos dos ornamentos da figura abaixo, composta por duas páginas distintas da edição de 1919.
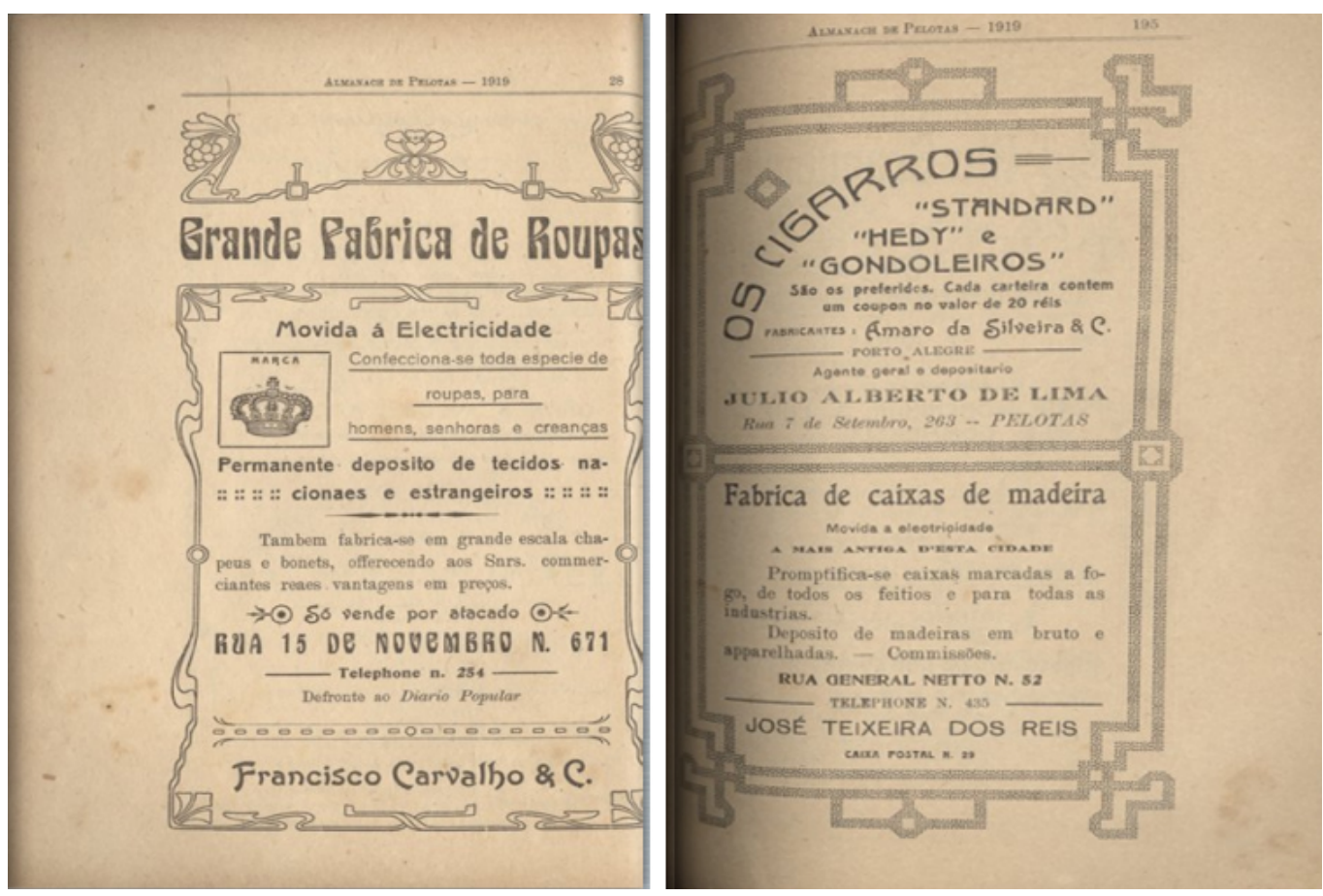

Figura 1 - Ornamentos em molduras nos estilos Art Nouveau e Art Déco em reclames (Grande Fabrica de Roupas; Julio Alberto de Lima / cigarros; José Teixeira dos Reis / caixas de madeira). Fonte: Almanachs de Pelotas 1919, p.28 e p.195. Acervo da Bibliotheca Pública Pelotense

As influências desses estilos, como dito, fizeram-se observáveis ao longo das páginas dos Almanachs, por meio da análise gráfica. Para desenvolver a análise, tomou-se de empréstimo a metodologia empregada por Fonseca (2012, p. 142-236) no estudo de revistas brasileiras do final dos anos de 1800, na qual ela aplicou como parâmetros de observação os itens capas, miolo, ilustrações especiais e vinhetas. Esses tópicos foram adaptados ao propósito da tese (LIMA, 2015) da qual se originou o estudo ora apresentado. Justifica-se a adoção de uma metodologia utilizada na apreciação de revistas ilustradas para os almanaques porque ambos os tipos de 
veículos impressos assemelhavam-se no concernente à inserção de conteúdos ilustrados com imagens.

A adaptação feita diz respeito ao uso das ilustrações no geral, ao acréscimo do item fotografias e à substituição do tópico vinhetas para ornamentos, nos quais se podem incluir eventuais vinhetas e os recorrentes fios e molduras. Assim, na tese (Idem), foram analisados: capas, miolos, ilustrações, fotografias e ornamentos. Já, para o estudo desse texto foram suprimidos os itens miolos e ornamentos por não apresentarem associações gráficas evidentes relacionadas aos discursos de gênero. Além disso, esclarece-se que, das 23 edições, serão apresentadas apenas algumas amostras em cada um destes itens que serão analisados.

Referente às capas, nos Almanachs de Pelotas, o papel empregado é sempre de gramatura maior e mais liso do que o dos miolos. Evidencia-se, na maioria delas, a impressão feita em tipografia e, em algumas, a litografia, por vezes combinada com o uso de clichês fotográficos. Acredita-se que o emprego da litografia para materialização das capas deu-se no intuito de tornar estas mais atrativas, devido as possibilidades permitidas pelo referido processo (desenhos mais livres e emprego de mais cores). Leitura semelhante no que diz respeito ao impacto visual causado se faz com relação à utilização de imagens fotográficas nas mesmas. Já as capas com impressão tipográfica, também em função das possibilidades do processo, neste caso, de suas limitações, observam-se o emprego de menos cores. De maneira geral as capas são divergentes entre si, sem seguir um padrão determinado.

O exemplo de capa utilizado é o da edição de 1926, com impressão litográfica, de todas as amostras, é a que possui as cores mais vivas, contrastadas entre frias (azul) e quentes (vermelho e amarelo). Essa capa contém uma coluna e uma figura feminina em estilo greco-romano. A mulher, seminua, envolta por tecido, portando uma corneta, anuncia o ano, bem como pode ser traduzida como anunciadora de novidades no geral, questões caras para aquele contexto que auspiciava a modernidade. A mulher está sentada, tem o braço direito apoiado em um elemento gráfico que congrega parte de um reclame (Bataclan). Expressa o ambíguo diálogo entre elementos gerais da capa e reclames, recorrente no objeto de análise. A outra porção da propaganda, na direita daquela, apresenta o empreendimento, um ambiente de lazer no qual aparecem homens bem vestidos, bebendo e jogando bilhar. A composição, de forma geral, contém, ainda, rosas (inclusive a grande mancha vermelha no centro baseia-se na forma de uma), plantas e folhagens. 


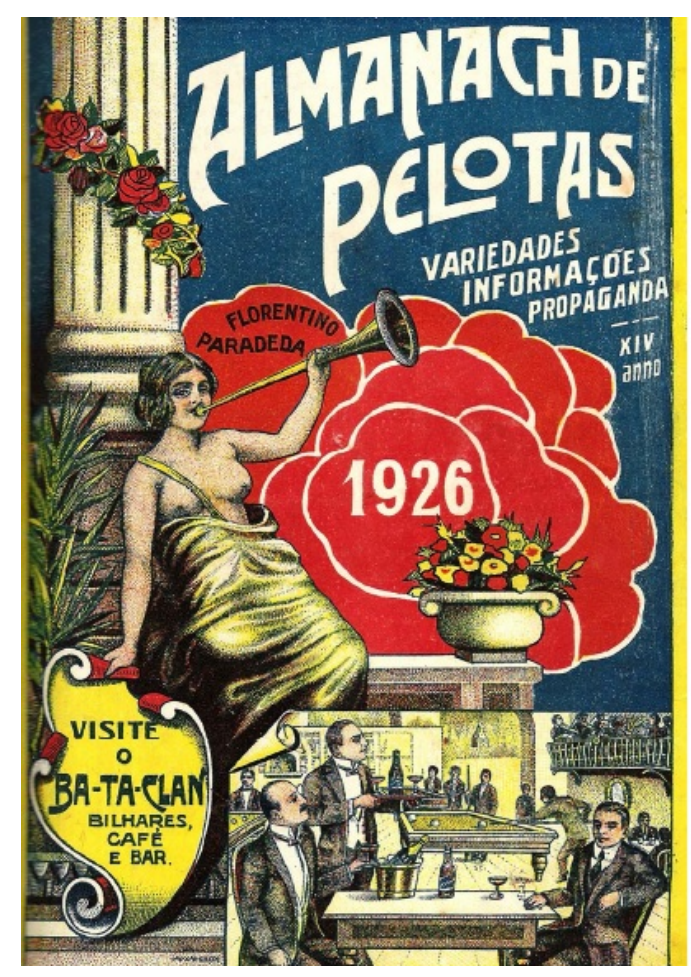

Figura 2 - Capa de 1926.

Fonte: Almanach de Pelotas 1926. Acervo da Biblioteca Rio-Grandense.

Há, nesta figura, um contraste de gênero a destacar. A mulher nua, dotada de encantos, figura o objeto central da capa. No entanto, ele se apoia em outro elemento de destaque, o reclame do Bataclan, que contém como narrativa um cenário composto por homens jogando e consumindo álcool. O reclame propagandeia um típico espaço definido por Luckow (2011, p. 127) como sendo de sociabilidade masculina. Estes espaços, para a autora, eram ambientes frequentados no fim de tarde, logo após o término do expediente de trabalho, onde os homens se encontravam, então, para beber, praticar jogos de azar, conversar sobre política, economia e participar de outros eventos artísticos. A presença feminina era vetada no local, sugerindo a associação do homem com o mundo público e da mulher com o mundo privado.

O próximo ponto de análise gráfica observou ilustrações com clichês de figuras femininas em vinhetas, como elementos decorativos e de finalização de textos, com os quais não estabeleciam nenhuma relação. Como hipóteses para as inserções destas ilustrações, sugere-se a necessidade de mostrar qualidade técnica e recursos imagéticos disponibilizados pela gráfica, de fazer aproveitamento de espaço ou de simplesmente ilustrar a publicação, condições desejáveis aos impressos do período. Essas imagens eram comuns após os prefácios e, também, após outros textos mais longos. 


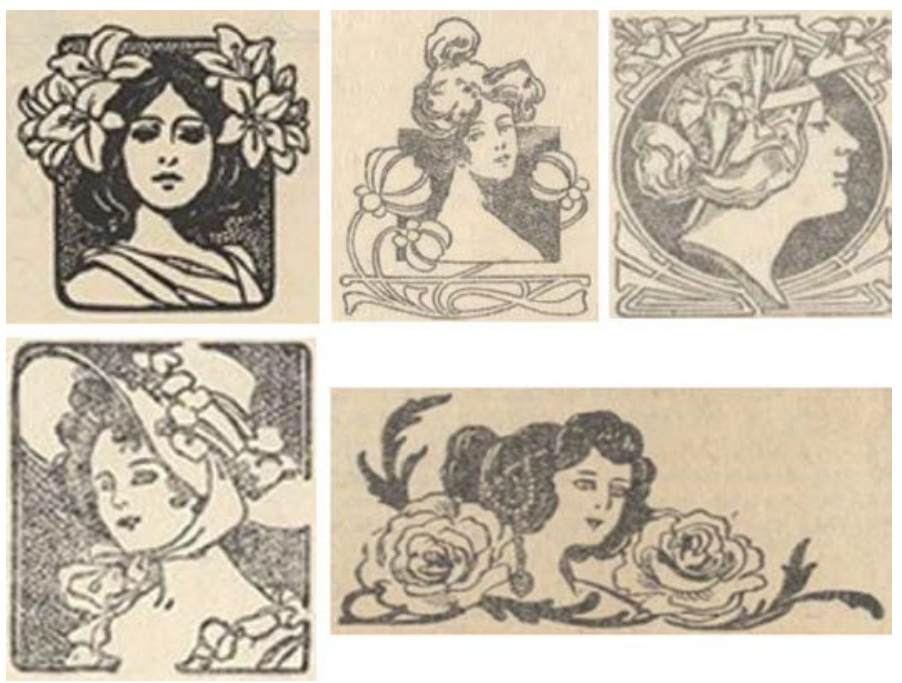

Figura 3 - Detalhes dos clichês com ilustrações de mulheres usados em vinhetas.

Fonte: Almanach de Pelotas. A primeira ilustração é de 1914, as próximas três encontram-se na edição de 1915 e a última na edição de 1927. Acervo da Bibliotheca Pública Pelotense.

As imagens sugerem a idealização de mulheres delicadas, belas, bem penteadas e rodeadas por adornos, em geral, florais, remetendo às influências do Nouveau. Realizadas com traço fino e com espaços preenchidos por tinta.

Iguais a esses clichês das mulheres, em vinhetas, foi encontrado apenas um contendo figura masculina (Figura 04), no ano de 1918. Ainda que também empregado apenas com cunho decorativo, destaca-se o fato de que as figuras femininas, nesse quesito, apareciam em maior número.

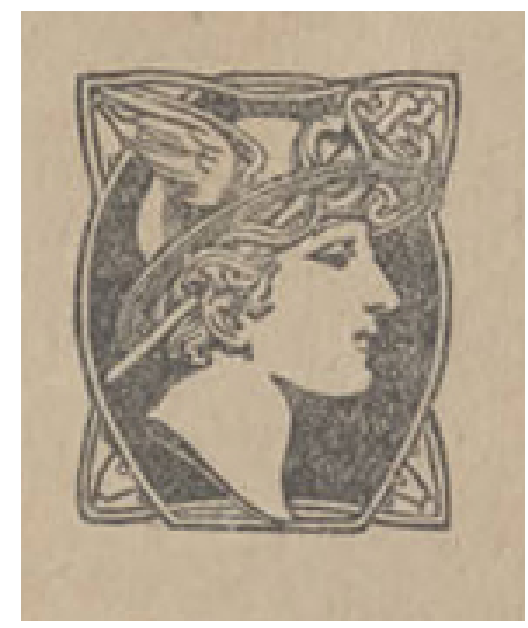

Figura 04 - Clichê com ilustração de homem usado em vinheta.

Fonte: Almanach de Pelotas, 1918, p.4. Acervo da Bibliotheca Pública Pelotense.

Nos exemplos acima, tanto na figura da capa, quanto nas das ilustrações, as mulheres são apresentadas com ênfase na beleza, predicado considerado, segundo Del Priore (2013, p.69), uma obrigação feminina. Tal predicado é usado, então, como um recurso para caracterizar os diferentes gêneros: ao passo que as mulheres eram idealizadas e identificadas a partir da beleza - atributo que passou a representar corpos saudáveis - os homens tinham como principal aspecto de caracterização a força 
física e a virilidade. Assim, era indesejável que as mulheres fossem feias e, os homens, fracos (MACHADO, 2007, p. 6-7). Nos exemplares mostrados, vêem-se possíveis traduções dessas afirmações, já que as mulheres, como dito, aparecem dotadas de beleza e delicadeza e, o homem, mesmo que belo, aparece munido de um capacete alado.

Lembra-se que o periódico voltava-se ao público masculino o que confere com o que observou Bourdieu (2014, p.79-83) sobre a identidade feminina definir-se por suas experiências, as quais, por sua vez, pautam-se no corpo-para-o-outro. Portanto, as mulheres eram vistas como objetos simbólicos, objetos a serem olhados pelos outros, objetos bonitos, disponíveis, e no caso dos Almanachs, objetos gráficos ornamentais a serem vistos principalmente por um leitor masculino. Para o autor citado, até mesmo na construção de sua identidade as mulheres são colocadas em situação de dependência dos homens/dominantes, sendo dominadas por sua dominação.

Outro ponto a comentar é que a nudez feminina, presente na capa apresentada (Figura 02), pode ligar-se à ideia de Segalin (2010, p.138-139) de que muitas vezes as mulheres eram associadas ao mal, por serem dotadas de encantos que faziam os homens a elas sucumbir. Melhor explicando, esta ideia vem de uma associação histórica dos homens a Deus e das mulheres ao diabo, como resultado de um longínquo processo de "diabolização" da mulher no Ocidente, intensificado após o Renascimento e a Reforma, quando a Igreja se sentiu ameaçada. Assim, seus dotes poderiam ser vistos como recursos maléficos que poderiam fazer os homens fraquejar. Mais uma vez atrelava-se a mulher ao seu aspecto físico "obrigatoriamente" belo.

O último item da análise são as fotografias. O uso de clichês fotográficos nos Almanachs era constantemente exaltado como forma de valorizar o periódico. As fotografias eram usadas para ilustrar o conteúdo editorial (muito mais do que as ilustrações), prioritariamente das situações ligadas ao progresso da cidade e, igualmente eram frequentes os retratos de figuras ilustres, quase na totalidade, de homens. Além do conteúdo editorial, as fotografias eram usadas na ilustração dos reclames.

A grande maioria de fotografias era veiculada em uma página inteira, por vezes em folhas brancas de maior gramatura e lisura ou mesmo nas folhas de papel jornal. Em algumas situações as fotografias vinham em folhas de tamanho diferente, ou maiores ou menores, com dobras, num recurso que chamava a atenção pelo inusitado e que aumentava a possibilidade de interação do leitor com o artefato.

Nesse texto, apresentam-se fotografias mescladas ao conteúdo editorial e relativas ao registro de pessoas ilustres. Nas duas primeiras, observam-se os grafismos com elementos florais e linhas sinuosas, oriundos do estilo Nouveau, usados para tornar a composição mais interessante. Acrescenta-se, ainda, que é normalmente no registro de pessoas que ornamentos e/ou molduras mais elaboradas são agregados. 

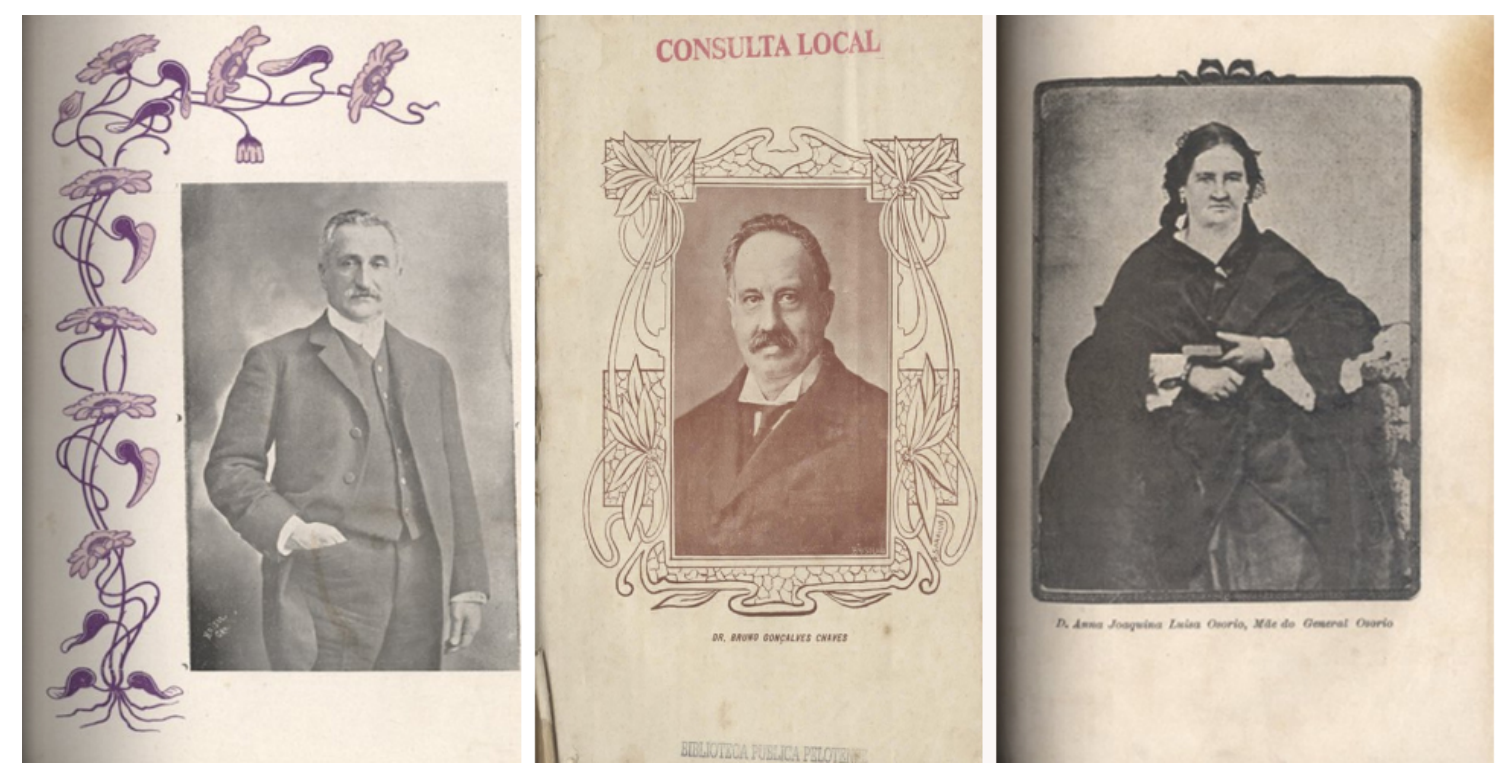

Figura 05 - Fotografias.

Fonte: Almanachs de Pelotas 1917, s.p., entre p.56 e p.57; 1924, s.p., antes da p. I; 1925, s.p., entre p.152 e p.153. Acervo da Bibliotheca Pública Pelotense

Sobre as fotografias, no entanto, as principais relações entre os gêneros podem ser feitas sobre um dado quantitativo. Fotos de homens são em maior número do que as de mulheres. Nos Almanachs de Pelotas foram contabilizadas um total de 601 fotografias. Dessas, 96 são retratos individuais de homens e oito, de mulheres. Há que se ressaltar, ainda, que o exemplo mais a direita da Figura 05 refere-se ao único caso de retrato individual feminino ilustrando conteúdo editorial. Além disso, enfatiza-se que a retratada era uma mulher de extrema relevância social, a mãe do General Osório, figura exponencial no panorama político da cidade.

\section{CONCLUSÃO}

Os primeiros aspectos gráficos comentados versaram sobre uma orientação dos estilos Art Nouveau e do Art Déco, dos quais não se fez nenhuma relação com a construção de gênero. Tendo-se em vista o contexto de veiculação dos Almanachs de Pelotas, é curioso comentar, apenas, que no caso das fotografias, há a presença mais evidente de elementos florais (típicos do Nouveau, inclusive de inspiração em curvas femininas) ornamentando as imagens masculinas. Assim, pelo exposto, esses estilos, mais do que qualquer outra aplicação ou motivo que se possa vir a encontrar, eram empregados como indicativos do novo e da modernidade, em uma publicação de cunho bastante conservador no tocante a hábitos e comportamentos, nos quais se podem se enquadrar as relações de gênero.

$\mathrm{Na}$ capa eleita para a apreciação gráfica, algumas noções dos espaços reservados para mulheres e homens também pode ser observada. Nela aparece um espaço de sociabilidade marcadamente masculina, no qual eles, "homens do trabalho" (como explicitado no prefácio de 1913), tinham o direito ao desfrute após o dia de labuta. Tais locais de diversão eram vetados às mulheres, sugerindo que a elas competia o interior dos lares.

No entanto, nessa capa a figura principal é a de uma mulher seminua, cuja sua caracterização de beleza coincide com as ilustrações femininas apresentadas no item 
seguinte de análise. Além de belas, as mulheres eram bem penteadas e sustentavam olhar e sorriso meigos. Essas mulheres deveriam ser, conforme observou de Del Priore (2013, p.69), obrigatoriamente belas.

As ilustrações apresentadas tratam de um único caso no qual as mulheres aparecem em maioria se comparado aos homens: as vinhetas ornamentais. Novamente, remonta-se a Bourdieu (2014, p.79-83) para associá-las ao sentido das mulheres vistas enquanto objetos belos e simbólicos para serem olhados. Nas ilustrações em geral, nas fotografias e nas assinaturas de textos, as mulheres estão em menor número nos Almanachs, indicando um processo de invisibilização, possivelmente desejável em uma publicação cujo público principal era o masculino.

Nesta linha de convergência, compete falar sobre o último ponto de observação, as fotografias. Nesse, é o maior número de fotografias com homens que sobressai. Esse texto foi ilustrado com o caso específico dos retratos. Já se ponderou que se tratava de uma publicação masculina, mas, em se tratando de um periódico que queria apresentar a vida na cidade, o que justifica a maioria de homens em fotografias em um cenário populacional praticamente equânime, no concernente ao sexo? A diferença é significativa: 96 retratos individuais de homens contra oito de mulheres. Além disso, apenas um retrato de mulher encontra-se no conteúdo editorial (os demais são em reclames) e registra uma mulher cuja importância é ser mãe de um destacado político da cidade. Os números reiteram o fato de serem os Almanachs, artigos de leitura para os homens, aqueles descritos no prefácio da sua primeira edição como os chefes de família e do trabalho, afirmação, por si, indicativa dos papéis sociais do gênero. Como resultado ou razão, percebe-se que nas páginas dos Almanachs, as mulheres esvanecem.

Assim, reportar ao passado (através de objetos que continuamente lembram hábitos e comportamentos desejáveis) para compreender o presente parece ser elucidativo, na medida em que, pelas análises observam-se discursos que ainda ecoam, mesmo se consideradas a sua diminuição. Por fim, entende-se que se esses objetos gráficos, pelos seus muitos apelos simbólicos, poderiam influenciar e refletir aquele contexto, considerações que podem ser aplicadas em veículos e mídias atuais, cujas análises são igualmente necessárias para que se percebam os sentidos arbitrados ao gênero.

\section{FONTES}

PARADEDA, Florentino. Almanachs de Pelotas (1913 - 1920). Pelotas: Officinas Typographicas do Diário Popular. Acervo Histórico da Bibliotheca Pública de Pelotas.

PARADEDA, Florentino. Almanachs de Pelotas (1921 - 1928). Pelotas: Tipografia A Guarany. Acervo Histórico da Bibliotheca Pública de Pelotas.

PARADEDA, Florentino. Almanachs de Pelotas (1929 - 1935). Pelotas: Tipografia Livraria do Globo. Acervo Histórico da Bibliotheca Pública de Pelotas.

\section{REFERÊNCIAS}

BARROS, Claudia López; FERNÁNDEZ, José Luis; PETRIS, José Luis. La ciudad y la prensa: los medios gráficos frente a las transformaciones de Buenos Aires. In: GUTMAN, Margarida; REESE, Thomas (orgs.). Buenos Aires 1910: el imaginário para uma gran 
capital. Buenos Aires: Editorial Universitaria de Buenos Aires Sociedad de Economia Mixta, 1999. p.241-253.

BOURDIEU, Pierre. A dominação masculina. Trad. Maria Helena Kühner. 12a ed. Rio de Janeiro: Bertrand Brasil, 2014.

DEL PRIORE, Mary. Histórias e histórias de mulher. São Paulo: Planeta, 2013.

DENIS, Rafael Cardoso. Uma introdução à história do design. São Paulo: Edgard Blücher, 2000.

FONSECA, Letíca Pedruzzi. As revistas ilustradas A Cigarra e A Bruxa: a nova linguagem gráfica e a atuação de Julião Machado. Tese (Doutorado em Design) Pontifícia Universidade Católica do Rio de Janeiro, Departamento de Artes e Design, 2012.

GASTAUD, Carla; SILVA, Fernanda Oliveira da. Dicionário de História de Pelotas. Beatriz Ana Loner, Lorena Almeida Gill, Mario Osório Magalhães (organizadores). Pelotas: Ed. da Ufpel, 2010.

LESCHKO, Nadia Miranda. Inventário para a Memória da Indústria Gráfica em PelotasRS1920. Dissertação (Mestrado em Memória Social e Patrimônio Cultural) Universidade Federal de Pelotas, UFPel, Pelotas, 2011.

LIMA, Paula Garcia. Memórias do feminino através dos reclames dos Almanachs de Pelotas (1913 - 1935). Tese (Doutorado em Memória Social e Patrimônio Cultural) Universidade Federal de Pelotas, Pelotas, 2015.

LUCKOW, Fabiane Behling. Chanteuses e Cabarés: a performance musical como mediadora dos discursos de gênero na Porto Alegre do início do século XX. Dissertação (Mestrado em Música) - Instituto de Artes, Universidade Federal do Rio Grande do Sul, UFRGS, Porto Alegre, 2011.

MACHADO, Vanderelei. A saúde da mulher e a virilidade masculina: imagens de corpo e gênero em anúncios de medicametos - Florianópolis (1900-1930). Nuevo MundoMundos Nuevos, v. 7, p. s/n-s/n, 2007. Disponível em: <http://nuevomundo.revues.org/index4013.html >. Acesso em: 4 set. 2009.

MEGGS, Philip B. História do design gráfico. 4.ed. São Paulo: Cosac Naify, 2009.

SEGALIN, Linara Bessega. Seriam os almanaques "leituras confiadas às mais inocentes e mais puras leitoras"?. MÉTIS: história \& cultura. Caxias do Sul, vol. 9, n. 18, p. 127153, jul./dez. 2010.

SCOTT, Joan Wallach. Gênero: uma categoria útil de análise histórica. Educação \& Realidade. Porto Alegre, vol. 20, n. 2, p.71-99, jul./dez. 1995. 